\title{
Response to Comments and Criticisms
}

\author{
Michael Ayers | ORCID 0000-0001-8289-2935 \\ Emeritus Fellow, Wadham College, Oxford, United Kingdom \\ michael.ayers35@gmail.com
}

\begin{abstract}
These responses are replies to the contributions to a book symposium devoted to my book Knowing and Seeing. Groundwork for a New Empiricism (2019), held at the University of Vienna in February 2020.
\end{abstract}

\section{Keywords}

perceptual knowledge - conceptualism vs. empiricism - knowing that you know KK principle - consciousness - self-knowledge

\section{Introduction: The Argument of Knowing and Seeing}

First, thanks to all who have contributed the thought-provoking articles to which I must now respond. I will start with a brief summary of the central argument of Knowing and Seeing, an argument initially motivated by a longstanding sense that too much recent and current epistemology in the analytic tradition has been founded on a couple of damaging errors.

First, it was widely accepted that Edmund Gettier, in demonstrating that belief can be both true and justified without constituting knowledge, had refuted the 'traditional' or 'standard' definition or 'analysis' of knowledge as justified true belief, setting philosophers the task of finding a better definition (Gettier 1963). That knowledge could be defined by a list of necessary conditions, starting with true belief, was for the most part simply assumed.

Second, the 'Cartesian' argument for scepticism had regularly been supposed to possess so much more than illusory force as to allow its frequent 'methodological' employment, as Descartes himself employed it in support of his Platonic rationalism, in order to promote some favoured account of what 
makes a belief knowledge as the 'only alternative' to scepticism. The current favourite ('coherentism' seeming to have had its day) is some form of 'externalism' such as 'reliabilism'. If there is something wrong with the Cartesian sceptical argument, however, we ought to be able to identify the fallacy more directly than by attributing it to a failure to have recognised the truth of one of these 'isms', none of which is without its own notorious difficulties. And if the argument is fallacious, it can hardly deserve the roles it has been afforded.

The first error, as to the significance of Gettier's squib, was already on the way to losing its long grip on analytic epistemology by the time I put pen to paper (so to speak). That was mainly, perhaps, from exhaustion, since the definitions offered as replacements for the supposedly 'traditional' analysis consistently proved to be either themselves open to the same kind of 'refutation' by counter-example, or circular, or both. But it was at least partly thanks to more accurate history, so that it was coming to be more widely recognised that the story of a 'traditional analysis' was unfounded. If any conception of knowledge was dominant from Plato to Locke, it was one that excluded the very possibility of the definition of knowledge as some class of true belief, since knowledge and belief were for millennia standardly supposed different in kind, mutually exclusive ways or species of (as Aquinas called it) 'thinking with assent'. Moreover, for Plato himself knowledge and belief have different objects, the object of knowledge being reality, 'what is', whereas the objects of belief are merely postulated or, as they were later called, 'intentional' objects.

Reflecting on that history with Maria Rosa Antognazza, my collaborator in a first chapter, I concluded that there are indeed grounds for some distinction of kind more or less at the place of the traditional knowledge-belief distinction, even for those of us who take 'belief' and 'knowledge' in the everyday, broad, non-technical senses, allowing that knowledge that $\mathrm{S}$ is $\mathrm{P}$ standardly brings with it belief that $\mathrm{S}$ is $\mathrm{P}$. We also felt that Plato's claim that knowledge and belief have different objects is worth exploring, given the striking differences between the forms of ascriptions of knowledge and belief in everyday language. We speak of believing propositions, statements, hypotheses, speculations, etc., but of knowing facts and (significantly) of knowing, and knowing of, people, places, objects, etc., in some accordance with Plato's claim that the object of knowledge is 'what is', reality. In a critical discussion of such ordinary speech, however, I conclude that, given the plausible, generally accepted view that there is a cognitive, and so causal link between the object of knowledge and the knowing subject, even 'facts', let alone 'propositions', are entities too abstract to be, in this sense, the objects of knowledge of the natural world, which must be supposed such material objects, events and states of affairs, etc. as are denizens of that world. In other words, we can draw a distinction 
between the content (or grammatically 'internal' object) and the ('external') object of knowledge, the entity of which we have knowledge. Belief as such has content, the belief believed, but has an 'external' object only in so far as it is about something of which the believer has knowledge, since our thought can only have reference to something of which we have at least some knowledge, however minimal (Ayers 2019, 95-129).

My first step in this programme, however, was to consider what it is about sense experience and perceptual knowledge that might justify the traditional anti-sceptical empiricist conception of the immediate 'evidence' of the senses' deliverances. Is there something about the perceptual experience that explains how it can be a source of knowledge without the support of further reasoning of any kind? The eventual conclusion of a detailed phenomenology of perception, examining in particular the role of proprioception and the integration of the senses, was that normal perceptual awareness of any feature of our environment carries with it perceptual awareness of the cognitive route - spatial and causal - by which that feature has become an object of our sense experience. Perceptual experience itself affords knowledge, not only of our environment, and of our place in it as a material object interacting with it, but also, simultaneously, knowledge of the causality of that knowledge. We know how, and so that, we are in cognitive contact with reality. That logically second-order knowledge, afforded without second-order thought or reflection, is a condition of our perceiving our environment as our environment, and makes an essential contribution to our capacity to interact appropriately with it. That is why I characterise perceptual knowledge as 'perspicuously' knowledge. It comes, as I put it, with its own credentials, containing within its content the answer to the question any assertion may face, 'How do you know that?'. In many other cases, our answer gives our reason for our belief that things are as we assert them to be. But to answer, e.g., 'How did you know that it moved?' by 'I saw it move', or 'I could feel it moving', is not to give the reason for a belief, but simply saying how we know (and therefore believe). Perceptual knowledge is not based on reasons, any more than our understanding why (and so our knowledge that) if $a=b$ and $b=c$, then $a=c$ is based on reasons for believing that proposition. If there were not some things that in the right circumstances we can just know, and know that we know, thanks to our basic cognitive faculties, we wouldn't know anything. Which is not to say that those faculties are infallible.

All this, I suggest, goes to explain the paradigmatic status of perceptual knowledge both in traditional philosophy and in everyday talk of knowing by 'seeing', literally or metaphorically, what is so. As Aquinas puts it, 'those things are said to be seen which, by themselves, move our intellect or senses to knowledge of them', 'by themselves' meaning without what Locke called 'extraneous 
reasons'. It also motivates my distinction between 'primary' and 'secondary' knowledge, which, on the evidence of the articles above, would appear less than clearly explained, and which I will therefore try to clarify now and, as appropriate, in responses to particular articles.

The dominant partner in this distinction is 'primary knowledge', 'secondary' knowledge being knowledge that isn't 'primary'. In other words, the distinction is just a way of picking out, from all that is properly counted as 'knowledge', knowledge deriving from the immediate and perspicuous apprehension of reality or truth. To be clear, I do not see myself as offering a definition, both comprehensive and explanatory, either of knowledge or of primary knowledge, still less of secondary knowledge. I have given an account of primary perceptual knowledge in terms of 'immediacy' and 'perspicuity', and that does something to capture the kind of analogy or relationship to the paradigm that might earn the title 'primary' in other categories of knowledge. But just how is it, for example, that the immediate grasp of such truths as that $2+2=4$ or the Principle of Identity is analogous to the immediate, pre-conceptual awareness of the physical layout of our environment and our place in it, along with an awareness of our cognitive relationship to it, that is delivered by the senses? Well, neither calls on 'extraneous reasons' or inference, and 'in a way' the mathematical or logical truth is the immediate intentional object of understanding as our environment is the immediate object of perception. But what about a theorem that calls for a complex proof? Is achieved knowledge of its truth 'primary' or 'secondary'? Well, however complex a valid proof may be, the ability to follow it will call sequentially on the subject's ability to 'see why' each step is valid. Consequently, that a theorem cannot be immediately 'seen' to be true without proof doesn't prevent mathematicians' knowledge that it is true from being 'primary' - which is why the tradition allowed it to be 'knowledge', discursive or demonstrative knowledge. Locke's example of justified true mathematical 'belief' is not a case of believing a theorem requiring complex proof, but one of being told by an expert that a theorem is true, a case that, in ordinary, everyday life and speech might count, in the right circumstances, as knowledge, and so, in my terms, as 'secondary' mathematical knowledge. Locke, of course, wouldn't allow that I have 'knowledge', whatever the circumstances, since it depends on 'extraneous reasons'. An analogous primary-secondary distinction can also be applied to memory, and to recognition (Ayers 2019, 64, 76-77), a point to which I will return.

All ascriptions of knowledge, whether "primary' or 'secondary', have implications as to objective certainty. Anyone who claims knowledge that P implicitly claims that it is objectively certain that $\mathrm{P}$, and vice versa. 'I know that it will rain but it is not certain that it will rain' is a kind of contradiction comparable 
to 'It will not rain but I believe that it will rain'. This close link between knowledge and certainty is, of course, at the heart of the 'Cartesian' argument, since the sceptic aims to undermine claims to perceptual knowledge by offering possible alternative explanations of our sense-experience, and if it's possible that not-P, then it's not certain that $P$. The question is, do sceptics offer examples of the right kind of possibility? To cut a long argument short, the requisite possibility is (tautologically) 'epistemic' and a state of affairs is epistemically possible if, relatively to such particular evidence and experience as is available, it has a probability greater than zero. What the Cartesian sceptic attempts to do is to supply a general reason to doubt all and any of the deliverances of the senses. That is so whether, like Hume, they assume the either false or irrelevant principle that whatever is 'conceivable' is possible, or whether, as in many current formulations, they rely on the general fallibility of our faculties and the accordant 'defeasibility' of their deliverances.

We'll come back to this issue, and the relationship between objective certainty and 'defeasibility'. But it may help towards understanding that difference, and the irrelevance of defeasibility to the sceptical argument, to reflect on the point that claims in logic and mathematics, supported by however convincing or, indeed, sound a proof, are still 'defeasible.' 'Reason' is not infallible, and there are illusions of reason as well as sensory illusions (the apparent force of the sceptical argument is one of them). Accordingly, any purported a priori proof is in principle open to question or refutation by unforeseen logical or mathematical argument: that is, it is 'defeasible'. But all that means is that debate and enquiry, in these as in all fields, are in principle open-ended. What it doesn't mean is that objective certainty is impossible in logic or mathematics or, one rather hopes, philosophy.

So much for the skeleton of my main argument, which is 'groundwork for a new empiricism', as my subtitle has it, in that it is offered as a fresh explanation of the authority of the senses, and is focussed on the basic, pre-theoretical, preconceptual, purely perceptual knowledge of our environment and our place in it afforded by their deliverances - knowledge of a kind that according to sceptics, old-fashioned rationalists, and conceptualists, for their different, but related reasons, we don't and cannot have, but which, for my 'new empiricist', is a precondition of our having any knowledge at all, and upon which we rely throughout our daily lives.

Nevertheless, it is a digression from this argument, added to the penultimate draft in response to criticism, that seems to have received the most sustained attention. That is the critical discussion of conceptualism in Chapter 3 and Section 6.6, which starts with some potted history, but becomes focussed 
on the explanations of perceptual knowledge and the response to scepticism offered by John McDowell. I was, and am, persuaded of a need, in the present state of philosophy, not only for such set-piece critiques of neo-Kantian conceptualism or intellectualism, but for more continuous explanation of how and, more importantly, why the realist empiricism for which I am arguing differs from it. So despite the topic's being, in a sense, subsidiary to my main argument, it seems appropriate to respond to it first, taking advantage of Charles Travis' fairly comprehensive exposition of a kind of conceptualist realism owing more to Frege than to Kant, along with Menno Lievers' assessment of the advantages of a view more like McDowell's. The article by Sofia Miguens and Naomi Osorio-Kupferblum offers an independent view of the debate.

\section{Empiricism and Conceptualism}

Here are two fundamentally opposed theories of knowledge and perception. One, call it 'conceptualist' (aka 'intellectualist' or 'rationalist'), supposes that the capacity to have knowledge or, indeed, beliefs, even perceptual knowledge, calls on 'reason', the capacity for logically structured thought - in effect, language. The other, call it 'empiricist', takes it that some knowledge of the world, afforded by the senses, is a condition of acquiring language, and so of any more systematic knowledge.

Conceptualists have their reasons, empiricists have theirs. To complicate matters, philosophers on both sides of that division may have different motives from others on the same side. Of those analytic philosophers who see themselves in the tradition of Kant and endorse his pronouncement that 'intuitions without concepts are blind', few, if any share his extraordinary motivation for pronouncing it. I target John McDowell in Knowing and Seeing, but McDowell himself shifted to a more abstract form of conceptualism than he first expounded. Charles Travis and J.L. Austin (to whose views, along with Frege's, Travis appeals in his present article) differ from both McDowell and from each other. But there is much they all have in common.

As for empiricists, they may agree that the senses continuously deliver such knowledge as allows us to live and act in the world, assuming that language and more abstract or theoretical knowledge comes later, but there may be disagreement (e.g., between 'direct realists' and 'phenomenalists') over what counts as an example of perceptual knowledge, over the metaphysical status and form of the objects of that knowledge, or over just how it is that perceptual knowledge underlies, and makes possible, other kinds of knowledge, e.g., 
in mathematics or fundamental physics. They may also disagree over what should be counted a sphere of knowledge - e.g., whether there is such a thing as ethical or moral knowledge.

In the following discussion I will stick to my own 'direct realist' version of empiricism, founded on a detailed phenomenological analysis of perceptual experience (Ayers 2019, especially 34-63). That analysis explores the crucial role of proprioception and the integration of the senses and control of our bodies in (so to speak) placing us cognitively in our environment as an animated material object interacting with that environment - notably with other material objects and stuff, not least with biological individuals. That is the place where, with the aid of memory, knowledge commences, and it is the natural operation of the senses that gets us there, not reasoning or the linguistic capacity that enables us to formulate logically articulated propositional thoughts, or to impose a world-creating 'conceptual scheme' on undifferentiated sensory input. To my mind, the view that animal sense experience does not, of its very nature, afford knowledge of the world, is deeply, wildly implausible. To perceive anything is to acquire some knowledge of reality (ibid., 107). I suggest that coming to the use of the senses is like learning to walk, something that in appropriately stimulating circumstances happens naturally in human beings as in many other animals (ibid., 180-185). It is, ipso facto, learning about the world and learning to act effectively in the world. It necessarily calls on a capacity not only to notice similarities among what is perceived at one and the same time, but also so to remember or 'recognise' similarities over time as to enable learning from experience. But that capacity, so far from requiring language and a grasp of predication and logical structure, is pretty clearly a precondition of acquiring them.

Conceptualist accounts of perceptual knowledge differ in the role accorded to concepts and propositional form in achieving it. Kant's 'transcendental idealism' would seem to leave no room for 'intuitions without concepts'. For him, human experience is of a world already structured by the 'forms of judgement' (i.e., by reason), an idea reshaped by P.F. Strawson's presenting his topic as 'our conceptual scheme', with the corollary that 'sensible experience itself comes permeated with those concepts of objects which figure in ... [our perceptual] judgements'. McDowell's contention that concepts that are 'actively' employed in judgement are 'passively' employed in perception is a gloss on Strawson. Travis, on the contrary, sees light between sense experience and the propositional judgements as to what is perceived that he deems a necessary condition of knowledge. That would appear to be Austin's view, too.

For Travis, the senses are 'silent', for Austin, 'dumb'. For Travis, that is because a condition of having perceptual knowledge is to have recognised that 
a predicative 'thought' or proposition - that is, a potential 'truth-bearer' - is satisfied by undifferentiated perceived reality, 'things'. Since that couldn't be achieved by someone who lacked language, it would follow that infants and animals cannot know anything - in effect, that our knowledge can extend no further than our capacity to state what we believe.

Perhaps the words 'true' and 'false' are most at home when applied to what logically structured statements and assertions state or assert - to 'propositions'. But the words are used in other contexts: photographs, for example, may require certification as 'true likenesses' of their subject, and we can intelligibly speak, if a little paradoxically, of 'false memories'. Travis himself describes the relation of propositions to the world (to 'things') as 'representation', but there are other forms of representation than descriptions. More to the immediate point, any of the ways we - including infants and many other animals - take things to be are so related to the way things are as to be open to assessment, if not as 'true' or 'false', then by means of more idiomatic equivalents. Memories of events, like maps, can be accurate or inaccurate. Philosophers have often resorted to distinguishing between 'veridical' and 'falsidical' sense experience, and whatever's wrong with the implicit model, the terms themselves are useful enough, since there's clearly a distinction to be drawn with respect to the relationship to reality of such experience. That is why the metaphor of the senses 'informing' or 'deceiving' us is so commonplace. Of course, if we are to give an account of what some person or animal believes, knows or notices, we do have to say it, and what we say will have propositional form, following 'that...' (or equivalent), as: 'Fido believes/knows/hopes that Mary is going to take him for a walk' ('... believes her to be about to...'). But that doesn't entail that the subject to whom knowledge or belief is truly ascribed has a thought with propositional form, or possesses the concepts that we employ in ascriptions of that belief or knowledge. So how truth enters into an ascription of knowledge or perception, ' $\mathrm{X}$ believes, knows/sees that $\mathrm{P}$ ', whether $\mathrm{X}$ is a professor or a dog, is that a condition of the truth of that ascription is that the contained sentence, taken in the context of its use, expresses a truth.

\section{Response to Charles Travis}

\subsection{Primary Knowledge and Recognition 1}

Travis objects to my distinction between primary and secondary knowledge largely because he objects to the idea that we could acquire knowledge that $\mathrm{P}$ purely through the operation of our senses, without recognising that 'things' satisfy the 'thought' that P. As he puts it (Travis 2021, p. 575), 
perceptual awareness is thoroughly extensional where awareness-that is not.... So a transition from one to the other is never effected, though it may be permitted, by perceptual awareness alone. It must always exploit a capacity to recognise an object of perceptual awareness as ... instancing (or not) [a generality]. The work of perceptual awareness itself is just to make such recognisable (to one suitably equipped).

Accordingly, his examples of perceptual knowledge, as in many discussions by others, are of 'knowing-that' or, indeed, 'perceiving-that' where what is known presupposes wider experience of the world, as seeing that there is a pig on the sofa. Perception can, Travis thinks, ground knowledge, by presenting 'things as they are' that are open to description by someone suitably experienced and conceptually equipped. That means, he thinks, that the boundary between my 'primary' perceptual knowledge and 'secondary' knowledge based on inference will fall in different places for different people. Experience will allow some to recognise immediately what will for others be the conclusion of an inference from evidence.

The example Travis builds on my story of inference to the existence of a bear in the vicinity, however, is surely unconvincing. No bear is in view (or audible, etc.), so that knowledge that one is nearby has to be based on evidence, however good his Woodsman is at recognising and assessing the evidence. As Austin says, 'The situation in which I would properly be said to have evidence that ... an animal is a pig is that, for example, in which the beast itself is not actually in view, but I can see plenty of pig-like marks on the ground ... [etc.]' (Austin 1962, 115). What is supposedly 'in view' and so 'recognisable' by the Woodsman is the situation, 'bear in the vicinity' - indeed, 'three-year old male black bear here within the last twenty minutes' (which reminds me of the old schoolkid joke, a picture of an aeroplane that has just flown out of sight). Apparently that counts for Travis as immediate perceptual knowledge that there is a bear around, unlike a less expert inference to a similar conclusion. The Woodsman's knowledge, Travis thinks, satisfies my account of 'primary knowledge', while my example of 'secondary knowledge' based on inference (together with there being no epistemically possible alternative explanation) is not, in his view, knowledge at all, just reasonable belief.

A less complex example that at least avoids Austin's point: one person might immediately recognise chairs as genuine Chippendale (or not), where another has to go to books, conduct tests, count tree-rings, and search out provenance before judging on the basis of such evidence. Travis would apparently accept that only the first case is a case of having 'proof', as if evidence can support belief but can't establish the objective certainty necessary for knowledge. On 
the contrary, I'd put more trust in the inference from evidence than in simple 'recognition' if I were buying Chippendale chairs, though I wouldn't deny that I'd appreciate an honest expert's assurance that they do 'look right' (and it might be more economical to get that first). But then an expert knows what to look for, can usually give their reasons for ruling out other possibilities, and in any case may insist on establishing provenance back to the workshop before claiming knowledge (in effect, that it is certain) that the chairs were by Chippendale. When what is at issue goes beyond sensible qualities, shapes, patterns, movements and the like, the difference between 'recognition' and 'inference' can become blurred. But it should be clear that Travis' charge that my distinction is one of grades of knowledge is unjustified, and that his interestingly traditional view that inferential knowledge is not knowledge is not in accordance with how we normally use the word 'know'.

\subsection{Primary Knowledge and Recognition 2}

It should help to clarify the issues to say more about recognition and about what constitutes 'perceptual' knowledge and, indeed, 'primary knowledge'. Many examples of knowledge that pass in analytic philosophers' arguments as perceptual knowledge presuppose the subject's recognition that what is perceived satisfies concepts possession of which would require more or less sophisticated background knowledge. Discussions of perceptual knowledge often focus exclusively on such cases as seeing that there are cookies in the jar, that there is a zebra in the enclosure, that Olga is playing chess, that there is a pig on the sofa. That raises the questions, (1) whether there is such a thing as 'purely' perceptual knowledge, knowledge that is 'pre-conceptual', and, for me, (2) whether such examples of knowledge can count as 'primary' knowledge.

That we have purely perceptual, pre-conceptual knowledge is established, I believe, in the phenomenological analysis of perception and physical action offered in the second chapter of Knowing and Seeing. With scepticism as the ultimate target, I looked to identify what it is about sense-experience that, to adapt Frege's expression, 'wins' us a world - and does so, one might add, at a very early age. The resulting analysis serves in later argument, together with the notion of burden of proof, as a weapon against the sceptic. For it constitutes an explanation of how it is that our integrated sensory system itself affords just such immediate and perspicuous knowledge of our existence in a physically structured world as Descartes' sceptic denies that we can have. It was such preconceptual knowledge that in the first instance I dubbed 'primary', not because it is better or more certain than all other knowledge, but because it is afforded by the operation of our basic cognitive faculties and means of finding our way through the world, shared with many animals. This is a condition 
of any 'higher' knowledge that humans can aspire to through the medium of language. It might have been called 'primitive', but that would have risked the opposite misunderstanding, as if it were mere 'proto-knowledge'. It is not a ladder to higher forms of knowledge that we can kick away. It stays with us, and we rely on it throughout our lives.

Moreover, there are other forms of knowledge sufficiently analogous to count as 'primary' in being 'immediate' and 'perspicuous'. Just 'seeing' that and why some simple necessary truth is true is perhaps the most important in the history of philosophy and science. But as I have suggested, we might also distinguish 'primary' and 'secondary' memory and recognition. Primary recognition is both immediate and perspicuous, as when you immediately recognise someone as the person who lives down the road. Secondary recognition might be, e.g., recognising someone from a description or from a flower in their buttonhole, or, on the other hand, the experience of being immediately sure that you have met this person before, but you cannot recollect 'who they are'. In primary recognition of a person, there is no mystery to you as to 'how you know them'. Primary recognition of a 'sensible quality' might be, e.g., immediately recognising the colour of a shirt as the same as that of something previously seen, or recognising it as puce, but neither achievement requires that I see the shirt in a special way. I don't need the concept puce in order to see the shirt as puce, just as someone who has the concept sees it. That 'recognition' comes apart from perception appears in other ways. If I claim to know that your new sweater is ultramarine, there are two sorts of response to the question, 'How do you know that?'. In one context, 'I happened to see it in your cupboard' may be the more appropriate. In another, 'I used ultramarine paint on the shed'.

Similarly with 'I saw that it was a Lesser Horseshoe Bat' and other cases where recognition of the 'generality' in question goes beyond what is immediately sensible. Since both the perception of the individual bat and the recognition of its species may be both immediate and perspicuous, such a case could be classed as 'primary knowledge'. Is it primary perceptual knowledge? Well, a member of this species has a characteristic 'look' that (as far as I know) nothing else quite has, but knowledge of its species isn't the purely perceptual, pre-conceptual knowledge of one's environment that is delivered by the senses as we interact physically with that environment. Other concepts, other 'generalities' take us even further from what is 'purely' sensible or perceptible. Travis' Woodsman recognises 'signs of a bear nearby', and so knows that there is a bear nearby, but that is not, as Travis seems to suppose, perceptual knowledge. If we say that he 'sees that' there is a bear nearby, that isn't because the presence nearby of the bear falls within the content of his visual experience, an achievement of his sensitivity, his faculty of vision. He doesn't literally 'see' a bear's 
being nearby, or that a bear is nearby - which, of course, he, or someone much less expert, might have done in other circumstances (cf. Ayers 2019, 110-111).

\subsection{Awareness-of and Awareness-that}

Travis (2021, p. 574) tells us that, because they are abstract entities, 'objects of awareness-that [are not] potential objects of perceptual awareness'. Of course, we can't see or smell 'propositions' (or even, I guess, 'facts'), but the neat dichotomy Travis draws out of his claim is easily questioned. Take the sentences, employed in such contexts, let us suppose, as to state truths (same names, same people), 'Peter told Bill that Mary was kissing John', and, uttered later, 'That Mary was kissing John upset Bill'. What upset Bill? Not the proposition that Mary was kissing John, nor that Peter told him that fact (although that is a possibility too), nor even that the 'proposition' was true, but what he was told had happened, i.e., what 'made' the proposition true, the event, Mary's kissing John. The point is, perhaps, even stronger with 'Bill was upset because he saw that Mary was kissing John'. Again, what upset Bill was what he saw and noted, the event. Compare the rather barmy view, less fashionable than it was, that my desire that my grandchildren have happy lives is 'analysable' as an attitude to a proposition, a desire that the proposition my grandchildren will have happy lives be true. No, what I desire is the humanly long-term situation, my grandchildren's living happily. A desire that is specifically a desire that some statement be true is possible, e.g., if it was my answer to yesterday's exam question, or because I simply hope that a witness is trustworthy in whatever they say, but these are special cases, in special contexts.

How about the bald, bold claim that 'perceptual awareness' is thoroughly extensional, where awareness-that is not'? As a generalisation about forms of words (and what else could it be?), that won't do. It is true that, as I put it (Ayers 2019, 112),

apart from some employments (particularly of 'feel that...'),'that clauses' following literally employed verbs of perception serve to identify one particular feature of the perceived situation noted by the subject and so one particular piece of knowledge achieved by the knowledge-producing faculty in question.

But it doesn't follow that, in order to notice - take in, be aware of, pick out, pay attention to - something about a perceived situation, the subject has to possess the concepts that we employ in order to give some account of what that is. An infant may evidently notice that her mother is frowning, a dog may clearly have taken in that its owner has picked up its lead to take it for a walk, a 
lizard or frog may fail to notice, then, when it moves, come to notice - become perceptually aware - that there is a fly on a nearby stone, but the subject of none of these epistemic achievements need possess concepts or have (or have 'accessed') logically structured 'thoughts', even if they can in some way, to some degree, recognise and distinguish 'generalities' and likenesses as well as individuals. If the child couldn't do that much before learning to talk, if it wasn't to that extent at home in the world, how would it ever learn to talk?

Travis does not round off his claim by asserting that 'awareness-that' is thoroughly intensional, no doubt because ambiguities of scope are endemic with respect to achieved reference in the 'contained' nominalised sentences. But ambiguities of scope also occur with talk of knowing, having knowledge of, or being aware of some object, state of affairs or event, and the same goes for talk of 'seeing' such 'thick' entities. As I point out (Ayers 2019, 126-128), there's a perfectly natural and in some contexts correct reading of 'Livia knows of/is aware of Caesar's assassination' on which it is equivalent to one reading of 'Livia knows that Caesar has been assassinated'. So, too, with 'perceptual awareness': 'Fido is aware of/has seen Mary's preparations for a walk', in response to the question 'Why is Fido so excited?', is true only if Fido took in that Mary was preparing for a walk.

The deeper, more than linguistic point, however, is that it is impossible to perceive anything without acquiring some knowledge of the world (cf. Ayers 2019,107 ), and that goes for many animals as well as homo sapiens. That is one intended message of my analysis of the phenomenology of perception and its integration with agency. And as I have said, the neonate's coming to the use of its senses is, ipso facto, its learning about the world, finding its way in the world, and that necessarily calls on a capacity so to recognise similarities as to enable learning from experience, but that is far from being able to grasp or access a Fregean 'thought' or 'concept' - i.e., to describe something - and is a capacity possessed by many other species than ours.

Longworth's related point that knowledge, unlike perception, involves 'commitment' is at best a point of language, and weirdly unrealistic if 'commitment' were understood as a deliberate act of judging that must be taken in order to move on from mere perceiving to knowing, from perceiving 'things' to 'perceiving-that'. Our acceptance of what the senses give is involuntary, automatic, the default attitude that is part of our animal nature and concurrently shapes and permeates perceiving itself, binding it in with action. Think of the integration of action with perception as someone explores their environment, or immediately responds ('without a thought') with an appropriate action to a suddenly changing physical situation, or threads a needle, or paints a picture. Occasionally someone might have an experience, or possess knowledge, that 
supplies 'concrete reason' to doubt that how they are currently perceiving their environment is the way it is, giving rise to a kind of forced back-tracking and limited withdrawal of that default 'commitment'.

\section{4 'The Austinian Turn' 1}

J.L. Austin made two influential contributions to epistemology, the first in his 1946 paper, 'Other Minds', a response to A.J.T.D. Wisdom's extensive reflections on sceptical and anti-sceptical argument. Austin considers the challenging question liable to be put in response to any assertion, 'How do you know that?', making the important anti-sceptical point that, if someone gives a prima facie good answer in the form of an explanation of what (in a significantly chosen phrase) 'puts them in a position to know', it is not enough to refute them simply to argue that their reason for supposing that they know is not 'conclusive', or that given human fallibility, it could still be that what was asserted is false. The doubter must respond with a specific 'concrete reason' for the doubt, or the claim stands. A 'concrete reason' must be more specific than what 'could be' in the sense of what is 'conceivable', and must relate to what actually 'might' be the case in the particular circumstances. I suggest in the book (too rashly, as we shall see) that this point, with its reference to 'human fallibility', is a progenitor of the notion of 'defeasibility', a term much and variously used after its introduction in 1964 for a property of ascriptions, to oneself or to others, of knowledge, however acquired. In doing so, I took it that a 'concrete reason' is one that raises the 'epistemic' possibility (at least) that what is asserted and supposed known is not in fact the case. I go on to argue that the term 'defeasible' is best used in a way faithful to its origins in law. As a 'defeasible' right in law stands unless a limiting condition is fulfilled, and is not in any way weakened simply by being defeasible, so a well-grounded claim to knowledge is not weakened simply by being defeasible. It's a matter of the burden of proof. If someone who explicitly or implicitly claims knowledge offers a plausible explanation of 'how they know', the burden of proof is on the questioner to provide a 'concrete reason' for doubt, and there may be no such reason available. The same goes for an explicit claim that what is asserted is objectively certain (i.e., not a matter of our being certain, but of $i t s$ being certain, given available experience and evidence.) Accordingly, the 'defeasibility' of perceptual judgements does not entail that it is never certain that such a belief is true, or that a claim to knowledge can only be true if it is indefeasible (none are).

So far, so good, and that small part of Austin's argument supplies one half of what Travis calls 'the Austinian Turn'. Much of 'Other Minds', however, is to my mind vitiated by an assumption popular among analytic philosophers, if perhaps seldom so baldly stated (Austin 1946, 6o): 
any descriptive word is classificatory, involves recognition and in that sense memory, and only when we use such words (or names or descriptions, which come down to the same) are we knowing anything, or believing anything.

He builds up to this claim by considering possible explanations of how the speaker knows 'There's a bittern at the bottom of the garden'. Every answer he postulates has to do, directly or indirectly, with how the speaker knows that what's there is a bittern - even 'I heard it booming' (how many of us could recognise a bittern's boom?) and 'The keeper told me' (a 'keeper' sounds like someone who knows his bitterns). There's no mention of 'I saw it', the answer that might be of most interest if the exchange was between Norfolk ornithologists. Hearing is the sole sense mentioned, as if recognition and the ability to classify are the essential conditions of cognition (which etymology would suggest puts the cart before the horse.) Hence, 'the senses are dumb'.

Austin's motives were probably complex. He was an admirer of Frege (and translator of Frege's 1884/ 1968, conceptualist scripture), but already at least beginning to see an improved understanding of natural ('ordinary') language as the next step in philosophy. Indeed, 'Other Minds' ends with the suggestion, premonition of his later 'speech act' theory, that 'I know' is a 'performative' closely similar to 'I promise', as if knowing that $\mathrm{P}$ is explicable as 'being in a position' to say 'I know that P'.

I take it that Travis wouldn't follow Austin along quite that path. Yet he is led by Frege to the view that only when the perceived world is recognised as satisfying such a predicative 'thought' is there knowledge of it. In effect, for Travis as for Austin, until what is perceived is described, overtly or to oneself, there is no belief or knowledge. As might well have been said to Austin, that is not the way we use the words 'know' and 'believe'.

\section{5 'The Austinian Turn' 2}

For the second half of the 'Austinian Turn' Travis draws on Sense and Sensibilia, a book reconstructed by G.J. Warnock from sets of notes for lectures given from 1947 to 1959 on A.J. Ayer's phenomenalism (Ayer, 1940). A crucial passage comes in Chapter 10, on 'the pursuit of the incorrigible', illustrated by Ayer's view that we have 'incorrigible' knowledge of sense-data, though not of material objects. Austin argues in effect, surely correctly, that descriptive assertions, whatever category of thing is described, may, depending on the circumstances, be either certainly (or possibly) true or possibly (or certainly) false. However, in doing so, he suggests that Ayer's prime mistake is to suppose that statements fall into kinds such that all statements of that kind are either corrigible or incorrigible. 
Many kinds of sentences may be employed to make statements that are, he says, 'in fact incorrigible - in the sense that, when they are made, the circumstances are such that they are quite certainly, definitely, and un-retractibly true' (Austin 1962, 115). So if I say 'That's a pig', after carefully inspecting a pig before me, my statement "will be "incorrigible", nothing could be produced that would show that I had made a mistake' (ibid., 114). It seems clear from this unhelpful piling on of adverbs that Austin would not after all have made the distinction between the epistemic possibility of error and defeasibility - between 'incorrigibility' and certainty.

He is of course right that, in the right circumstances, sense-perception and recognition can afford knowledge and objective certainty, for example, that there's a pig here - and objective certainty is tautologically 'absolute' (you can't go better than a probability of 1 ). But his apparent emphasis on truth is misleading and irrelevant. Certainty entails truth, but truth does nothing in itself to ensure certainty. More to the point, the quarry of 'the pursuit of the incorrigible' is precisely a kind of judgements about a category of subject-matter such that the very idea of there being 'concrete reasons' for doubt is senseless, i.e., judgements that are 'indefeasible' in the sense I have recommended. 'Statements about sense-data' have not been the only candidates for that status. 'Reason' has been a popular choice as infallible faculty, and eternal truths as the subject-matter of incorrigible judgements. Now we can simply respond to philosophers engaged in that pursuit that certainty depends on how the judgement is grounded in the circumstances, not on the faculty involved or the general kind of subject-matter in question. Or we can attempt something more explanatory of what has gone wrong. And that is where a careful account of the notion of defeasibility, burden of proof, and the essential 'open-endedness' of inquiry or debate can prove useful, making plain the distinction between willo'-the-wisp incorrigibility (= 'indefeasibility') and objective certainty (cf. Ayers 2019, 157-163). Austin's distinction between what is conceivable and what 'might be' in the circumstances was not that one, after all, but seems simply to be the distinction between 'logical' and 'epistemic' possibility (cf. Ayers 2019, 137-143). Or perhaps he conflated certainty and indefeasibility - he was, after all, on fresh ground.

\subsection{Disjunctivism}

Travis' complex criticism of my take on McDowell's 'disjunctivism' misses my main point. First, I agree with McDowell not only in a number of his criticisms of scepticism, and, of course, his direct realism, but also that hallucinating a rat is quite a different mental state from seeing a rat, pointing out, indeed, that that difference isn't just a matter of distal cause, but could not but 
be neurological (Ayers 2019, 186-188). But sometimes people have such hallucinations (generally when sleepy or unwell, and/or drugged) as to lead them to believe that, e.g., someone has entered the room, and stands by their bed. McDowell contrasts this sort of 'bad case' with the 'good case': the false judgement in the bad case, as well as being 'excusable' but unjustified, is defeasible, but the good case, he says (McDowell 2009, 235),

- a case of an environmental state of affairs [being] directly present to one in experience - constitutes one's being justified in making the associated perceptual claim ... And this justification is not defeasible. If someone sees that $\mathrm{P}$, it cannot fail to be the case that $\mathrm{P}$.

Pace Travis, it really does seem, in context, that McDowell is trying to squeeze more out of that last sentence than a tautology. He has also said, "The warrant for a belief that the [perceptual] state provides is indefeasible; it cannot be undermined' (McDowell, 2011). He certainly seems to suppose that the 'good' state provides 'warrant' that rules out anything arising that would give cause for reasonable doubt, e.g., as to whether we really did see the table move, as we had supposed and claimed. If we take it that 'cannot' has the same force in each passage, it's difficult to see that he is not, rather like Austin, supposing that, to put it crudely, truth ensures certainty - i.e. rules out the 'in principle' possibility that 'concrete' (if misleading) reasons for doubt should arise. In other words, as I described a related move in my response to Longworth, he is ontologising an epistemic condition of knowledge, as if the way things are can close off the intrinsic 'open-endedness' of debate and inquiry. At the same time he has conflated the notion of 'defeasibility' with that of the epistemic possibility of error in particular cases.

\section{Response to Menno Lievers}

Lievers adopts a more neutral attitude than Travis to my opposition to 'conceptualism', but judges conceptualism to have clear explanatory advantages that represent a challenge to my empiricist view. Although, like Travis, he appeals to Frege, he takes a 'conceptualist' account of perceptual knowledge to be the view Travis rejects, that sensory experiences themselves have propositional content.

Nevertheless, the first 'advantage' Lievers ascribes to conceptualism is no different from Travis': it explains the place of truth as a condition of knowledge. If it is insisted that propositions are the only truth-bearers, however, 
then (to repeat from section 2 'Empiricism and Conceptualism' above) 'how truth enters into an ascription of knowledge or perception, 'X knows/sees that $\mathrm{P}$ ', whether $\mathrm{X}$ is a professor or a dog, is that a condition of the truth of that ascription is that the contained sentence, taken in its wider context, expresses a truth.' (Cf. 'Response to Travis', 'Awareness-of and awareness-that.')

With respect to another condition, that the proposition is justifiably believed, Lievers suggests that conceptualism explains how there can be a justifying relation between experience and belief, and by the same token meets the requirement (argued for by Cunningham 2018) that the items that justify perceptual beliefs ... be carriers of truth and falsity, because they are reasons for action'. Reasons for action, Cunningham argues, are more 'fine-grained' than can be explained by the perception of 'thick' objects of knowledge.

In effect, the answer to the last 'problem' deals with this one. The 'fine grain' is provided by the subject's noticing something in what they currently perceive that prompts appropriate action, as many animals do. The idea that anything like Fregean 'concepts' must play a role in noticing something is an 'illusion of reason' consequent on the fact that if we are to attempt to give an account of what is noticed, we have to 'employ concepts'. And the concepts will no doubt miss the correlative 'fine grain' of what is noticed, for we are back with the incommensurability of conceptual and non-conceptual content (Ayers 2004; 2019, 77-78). The alleged 'integration problem' calls, not for a conceptualist theory of perception or perceptual knowledge, but for the recognition that an account of the 'content' of perception is an account of its object (the environment) as it is perceived. Such an account no more requires that the content is structured by concepts than it requires that reality is structured by concepts. It's the account itself, not the world or sense experience, that has conceptual structure. The world has physical structure to which the senses give some access, and to which the structure of natural language owes a significant debt (Ayers 2005; 2019, 87-94).

Response to Mira Magdalena Sickinger

Mira Magdalena Sickinger's short 'Review' is largely expository, but she raises certain questions that call for answers.

\subsection{Secondary Knowledge}

Sickinger raises the question whether it is a requirement of inferential secondary knowledge of, e.g., the past existence of dinosaurs that the subject should be conscious of the grounds of the inference from fossils to the extent of being 
aware of all the reasoning and discoveries that explained what in the 17 th century seemed to some conclusive evidence against a biological explanation of fossils' origin: they are, after all, largely or totally mineral and, while often in the shape of sea-creatures, may occur at the tops of mountains. The alternative possibility proposed was simply that fossils grow in the earth as crystals do. Does someone lacking the biological and geological knowledge called on to meet that argument really know, rather than simply believe on the authority of experts, that dinosaurs once roamed the earth? Sickinger is inclined to answer 'No', but that is not how we think about what she herself calls 'collective knowledge', established by experts. My 'cognitive link' with the object of my knowledge that enables me to refer to William the Conqueror and know about what he did obviously does go through other people - scribes, historians, teachers and the like - not to say lifeless objects, manuscripts, books and so forth. There is, as it were, such a chain of cause and effect between object and subject, appropriately and sufficiently involving the use of basic human cognitive faculties, to justify ascribing knowledge to me, since it makes it certain that William lived at a particular time and did certain things, if much of his life is at best a matter of speculation. Very little of that 'cognitive link' may be 'perspicuous' to me in any but very general terms, and it certainly does call on other people to have established it. If I allow that kind of case to be one of knowing (not to mention the 'diffident student' to whom the link is entirely obscure), where, Sickinger asks, do I draw the line? Well, I aim to understand natural language, not reform it, and, I guess, like most other people, if pressed, I'd draw a fuzzy line that puts the diffident student's 'knowledge' on or very near it (hence 'peripheral'), whereas, thanks to others, my knowledge of the existence of dinosaurs, of the holocaust, of climate change falls well inside it. I leave it to the reader to list the pros and cons of counting the diffident student as having knowledge.

\section{2 'Cognition'}

Sickinger calls for an explanation of my (she suggests, problematic) use of the term 'cognitive', as in 'cognitive link'. What is 'cognition'? When I asked my computer, I was told 'the process by which we acquire knowledge', an account that will do nicely enough in an explanation of why cognition should not be thought of as something that occurs entirely within the mind or nervous system, at least when the knowledge is of the world. I have employed the terms 'cognition' and 'cognitive' with respect to the process that establishes or constitutes the requisite link between the object of knowledge and the subject's having knowledge of it. Being told something might thus be a part of such a cognitive process or link. Is that a problem? 


\subsection{Internalism and Externalism}

I do not make myself clear, Sickinger complains, on my position in relation to the internalism-externalism debate. I'm not sure that I can do better in response than to ask her to reread my introduction to Chapter 6 (p. 164-166), the ensuing criticisms of the 'externalist' arguments of Dretske and others, and my response to Longworth herewith. Of course, I reject 'internalism' in the sense that has Descartes as paradigm, and which is incompatible with 'direct realism'.

Longworth aims to present counter-examples to my account of ordinary conscious sense-perceptual knowledge of some feature, $X$, as 'primary knowledge', i.e. knowledge that is both direct and such that the subject knows that and how they have the knowledge, this second-order knowledge of our cognitive relationship to $X$ being itself acquired through the very same total experiences as afford the perceptual knowledge of $\mathrm{X}$.

He starts by considering my claim that our having any 'secondary knowledge', i.e. any knowledge at all, depends on our having some primary perceptual knowledge. He focuses on my 'blindsight' example and my claim that the supposition is incoherent that all our knowledge of the world might be 'secondary', in that we had (via the 'blind' operation of sense-mechanisms) reliably engendered true beliefs, but without knowing that and how we had them - without ever being in the 'perspicuous' cognitive relationship to our environment that we are in in everyday perceptual experience. Why is this supposition incoherent? More particularly, why would such true beliefs (given that they seem fully to satisfy a 'reliabilist' definition of knowledge) not count as knowledge unless we had, and exercised, a capacity for primary knowledge? Crudely, it's because it is only the person in the God-like position of making up the story who can build into it that the (arguably impossible) 'blind' beliefs are true and reliably engendered. If everyone within the story has only secondary knowledge, they can't know that. They can never know that they know, or, therefore, know anything. And it is hardly more than common sense that only someone who can experience their being in the environing world can have grounded knowledge of it. (Roughly, and in a nutshell, that's what's irremediably wrong with 'externalism'.)

Longworth now leads into an attempt to construct counter-examples with thoughts on the difference between perceiving and knowing. Although the object of both must exist or be the case, knowing, he says, unlike perceiving, 
involves a 'commitment' (roughly, I presume, belief) such as could exist without the knowledge, and which is subject to a 'safety condition' such that, unless that condition is fulfilled, it will not count as knowledge. That condition, he tells us, is that there is no significant danger or 'near possibility' that the commitment is erroneous, as there is in selected 'dead ringer' cases. For an example of such a case he takes us to the mythical fake-barn country, much visited by philosophers, in which there are so many fake barns that you cannot know that you are seeing a real barn even when you are.

It's worth noting right away that this explanation, and indeed the very notion, of a 'safety condition' is one that, as it might be put, serves to 'ontologise' what is at bottom a common-sense epistemic condition of the truth of ascriptions of knowledge: namely, the condition that what is said to be known is objectively certain. Since this is a hugely important point, I'll repeat my explanation. Objective certainty is inter-definable with epistemic possibility and probability: an event is certain to occur iff there is no epistemic possibility that it not occur, and it is epistemically possible that it occur iff there is a probability greater than zero that it occur. All are judged in relation to experience and evidence available in a particular situation, which is commonly here and now (as when we just ask, 'Is rain probable this afternoon?'). Certainty (and absence of possibility) is 'absolute' as probability, a matter of degree, is not. A judgement that it was certain or not epistemically possible that $\mathrm{P}$ in the past is vulnerable to events in a way a judgement of probability (between zero and one) or a positive judgement of epistemic possibility is not. It can't have been certain or known at $t$ that $E$ would occur at $t+2$, if now, at $t+1$, it is epistemically possible that $\mathrm{E}$ will not occur at $\mathrm{t}+2$. But that E's occurrence is not at all probable now is compatible with its having been very probable at $t$, or its becoming very probable in future. Now 'danger' is a matter of probability and epistemic possibility, but its absence is made to look like an ontological condition of knowledge by judging the probability from outside the story - as it were relative to the epistemic situation of its Creator - much as in the case just discussed. It is, indeed, a mistake endemic in externalist argument.

The need for a 'safety condition' of knowledge, then, boils down to the unmysterious point that an ascription to oneself or another of knowledge that $\mathrm{P}$ can be refuted by evidence that it is epistemically possible that not-P. In the absence of any such evidence, however, the ascription of knowledge that $\mathrm{P}$, such as a claim to have it, together with its implication that it is certain that $P$, may be perfectly well justified (contrary to the scepticism that assumes that, whatever the evidence, anything, however fantastical, is epistemically possible). Like any assertion or belief, however, even a true belief, an ascription of knowledge is 'defeasible' in the sense that, in principle, further, possibly very 
misleading (Ayers 2019, 174-180) evidence could come to light that afforded reason to doubt the ascription. But of course it must come to light before it can serve as reason for doubt, and it must come to light within a story before it can serve as a reason to doubt or to deny an ascription of knowledge within that story.

So my reaction to Longworth's somewhat improbable story, in which the 'dead ringers' are perceptual and hallucinatory experiences interspersed by a neuro-psychologist evidently omniscient and omnipraxic in their field, is along the following lines: - Whether the subject of the story has perceptual knowledge of the presence of the orange depends, not upon the mere occurrence of an intermixture of 'dead ringer' hallucinatory experiences with perceptual experiences, still less upon the mere fact that some experiences are perceptual (the subject does perceive the orange), but upon what other knowledge is granted to them. Since ascriptions of perceptual knowledge are, like any knowledge ascription, defeasible, the question whether at any time the subject has perceptual knowledge of the presence of the orange depends on whether that ascription of knowledge has been defeated, i.e. whether evidence constituting (possibly misleading) reason to doubt has emerged. Now, from our epistemic situation, some 'evidence' has come to light (since Longworth has told us!) that does defeat any ascription of knowledge to the subject by $u s$, if it is supposed that the subject is either blissfully unaware of the nature of the experiment, or is only aware of its general nature - that hallucinations will sometimes occur that are indiscriminable from perceptual experience. In the latter case, any self-ascription of perceptual knowledge is 'defeated' and no longer justified from the subject's standpoint as well as ours. But if the story were then to grant the subject much more precise knowledge of the experiment, so that the subject was supposed aware of just when the hallucinationmachine was switched on and off, then the subject would know when they were perceiving the orange, and so have perceptual knowledge of its presence, and when they were hallucinating. So it's not just the existence of dead ringers that matters as a spoiler of ascriptions of knowledge, but how and when evidence of their existence can serve as a reason to doubt what is otherwise properly and reasonably judged to be certain.

I am unmoved by Longworth's purported example of the possibility of having direct perceptual knowledge without knowing how one comes to have it: he postulates a subject who gains knowledge of what someone is saying to them by skillful lip-reading, while under the false impression that they are simply hearing it. First, such a case almost certainly couldn't happen in a human being in good shape. Hearing and sight, along with linguistic ability, would inevitably be mutually affective. Someone who is partially deaf, perhaps, might 
be unaware how much seeing the speaker's face contributes to their ability to make out what is being said to them (although I'd judge from personal experience that it's the speaker who is the less likely to realise that!). In any case, some facts as to the integrated, 'trans-sensory' way in which the senses work together are pretty surprising and only recently recognised, and no doubt there's more to discover. But such ignorance, past and present, has never stood in the way of our knowing that we are gaining knowledge of things by perceiving them - however unsophisticated 'we' are. In comparison, Longworth's subject is having a pretty sophisticated thought. But the important point is that the phenomenology of perception, and the question of how sense experience itself affords basic knowledge of the structured environment - 'things', the world - is empirical, not a matter of what is logically possible or imaginable. What is important to epistemology is to recognise how its doing so involves direct access, not only to our surroundings, but of how we are cognitively related to them, so that we know how and that we know.

Response to Rory Madden

In a short, ingenious article Madden advances an argument in criticism of my characterisation of 'primary knowledge' as both immediate knowledge of reality and 'perspicuous'. He complains, in effect, that I fail to include in my account of perspicuity the subject's awareness of the sense experience itself, although I claim that perceptual awareness of the environment includes awareness of the way in which the perceived environment causes that experience. He notes my apparently approving reference to G. E. Moore's notion of the 'transparency' of sense experience to its objects, as if nothing can be discerned or said of the experience itself. He notes, too, my reference to the 'independent' objects of perceptual experience, as if an object of perceptual experience is 'real' in so far as it is independent of that experience, whereas the experience itself could hardly be that. He cites some of my examples of how the causality of a perceptual experience of the environment - i.e., the causalcum-cognitive link between perceived object and perceiver's experience - is itself an object of that same experience as evidence that I make no mention of the experience itself the causality of which is in question, but end the story at the sense-organs. He apparently concludes that I am taking the 'transparency' metaphor too seriously and asks, 'if experience is nothing but a transparent window on an independently existing reality, then how could it possibly also tell us something about itself?' At the same time he notes my insistence that the experience by which we acquire primary knowledge must be 'conscious' 
without explanation (except by offering an intuitive contrast with blindsight) as to why that has to be so.

All this is accompanied by the offer of a way out: drop the 'realist' notion that all the objects of sense-experience are independent of that experience, and allow the experience to be 'reflexive' so that one of its objects is itself. That implies that sense experience is not simply 'transparent', and Madden offers convincing reasons for holding that features of the experience, such as its seeming to be an experience of what is present and happening now, are available to us together with its independent objects. For good measure he adds an example of a subject's attending to a visual experience, rather than to its independent objects.

Madden sees his proposal as offering an explanation of why blindsight does not afford primary knowledge. If conscious experience is supposed reflexive, there is no problem in the idea that the causal (cognitive) route from the perceived environment to the experience (and not just to the sense organs) could be an object of the experience itself. So 'blind' experience cannot have just the same content or objects, as conscious experience. Moreover, as he in effect points out, acceptance of reflexivity is in accordance with traditional accounts of consciousness (now called 'same-order' accounts).

How to respond? Well, I borrow Moore's metaphor of 'transparency' in a paragraph on the traditional appeal to the qualitative character of sense experience that distinguishes it from, say, imagination or dreams. That appeal invites the challenge to say what the distinctive 'character' of sense experience in general is. Moore's concern with sense experience is related: if we try to describe the experiencing, we find ourselves giving an account of its independent objects. The experience itself 'seems transparent'. I repeat the 'seems', since all this leads into an explanation of how we can after all give an account of perceptual experiencing. For I offer an explanation of the phenomenology of perception as 'at least in large part the attempt to give a systematic account of what is perceived, as it is perceived'. Accordingly, there is no way that a total account can be given of the experiencing itself that does not mention or presuppose its objects, as they are experienced - i.e., it's 'content'. So, to take Madden's example, in trying to describe the effect that wiggling my head has on my visual sensations, I might say that the things I see seem to be jigging around. As Madden argues, that might be the limit of my interest in the objects of sight in this case, but they nevertheless need to be mentioned if the effect is to be described. Many philosophers have, like Reid, treated physical pain as a paradigmatic pure 'sensation', but pain always has location, and that is because having a pain in a foot is being painfully aware of the foot (cf. Ayers 2019, 47n). So attending to how we experience things may well count as attending to our 
sensations or sense experience rather than to the objects of that experience. But that doesn't mean that being aware of the experience is separable from being aware of its objects (cf. Ayers 2019, 46-47). Why, in my explanation of 'perspicuity', do my examples of the causal-cognitive link between object and experience that is itself an object of that total experience so often seem to end at the sense organ rather than moving on in, as it were, to include the experience itself? Well, certainly not because I doubt whether we can be, or are, aware of our perceptual experiences. They are, after all, conscious - episodes of awareness of our environment, of our bodily selves and of our interaction, including cognitive interaction with our environment. But being aware of, say, a tactile sensation is not distinct from, indeed normally is, being aware of touching or being touched by something, being tactually aware of that thing. So to say that I can feel something pressing into me is to give an account of an experience.

More generally, I am deeply suspicious of any 'theory' or, worse, 'analysis' that is offered as an explanation of what consciousness is, as if, in this case, the notion of reflexive awareness, of mental states that have themselves as object as well as other things, was clearer than the notion of consciousness, and could be explanatory of the role of consciousness in nature and in our epistemic lives. I do not see how, for example, the importance to our possession of perceptual knowledge of our environment and capacity to act in it - of our consciously perceiving it - is at all explained by that model. If we were not conscious, we would be unaware, not only of the perceptual experience that in that case we wouldn't have, but of anything.

I will attempt to restate the position taken up by Maria Rosa Antognazza in her difficult, intriguing article, and to identify where there is disagreement between us.

To start with her claim that 'the first phenomenological datum ... is: something is present', we might ask in what way is this 'first', and so, presumably, prior to any distinction between ways in which things can be 'present'? One might say that to be aware is always to be aware of something, but that does not mean that a possible state of awareness is awareness simply of 'something'. So why is phenomenological priority given to what seems simply the most general (or vague) ascription of conscious awareness, supposed equivalent to Descartes' 'I think'? 
However that may be, Antognazza's next step is the claim that objects of awareness ('what is present') are either specifically experienced or 'lived' as 'mine', as modes of my being, or as 'other', as modes of being of an 'aliud'. So feeling cold and wishing to warm up is how 'I' feel, and is 'lived', but to feel the coldness of the snow is to experience coldness as a mode of being of something other than me. Here the personal pronoun, 'I', stands for 'whatever it is that keeps together or unifies [the former] modes of being, which are 'affective and conative/appetitive', rather than anything perceived. Perception, it seems, even proprioception, is on this view always of something 'other'. Antognazza associates her distinction, not implausibly, with Hume's views on personal identity, Reid's distinction between perception and sensation and Spinoza's account of the role of conatus. Perception, she holds, is the awareness on the part of a self 'primitively felt as the subject of appetites, drives, affects', of 'something "other" than itself impinging, as it were, on itself.'

There are formal similarities, at a certain level of generality, between her account, or significant parts of it, and the phenomenological argument of Chapter 2 of my book. For example, I wouldn't deny that 'Some aspects of what is present are phenomenologically experienced as modes of being of whatever it is that keeps together or unifies these modes of being', but as an 'animalist', I'd cash it out rather differently. At any rate, since Antognazza herself, towards the end of her article, irenically emphasises similarities and points of agreement, I will concentrate on what seems the main, radical difference between us.

As I understand it, Antognazza's self is not unknown, but it is first or immediately known only as the subject of those 'affective and conative/appetitive' states that are 'felt' or 'lived' as one's own, and reflection upon which can afford a more sophisticated form of self-knowledge. Like Hume's, but unlike mine, her self is not itself an object of perception. An important element in her account is her reference to Reid's perception-sensation distinction resting on his example of pain. However, his distinction seems to me to presuppose that we could identify and describe 'sensations', the 'affects', as states ('modes of being') of the mind or self, without mentioning the objects of 'perception', experienced as modes of what are 'other'. But as I have already argued above and elsewhere, although, as Reid remarks, felt physical pain is not distinct from our feeling it, and is not an object of perception, nevertheless feeling the pain is essentially a way of perceiving something, since it is being proprioceptively aware of a part of oneself in a painful way. The logic of Antognazza's account would make proprioception and indeed all forms of perception of one's own body, awareness of something 'other', whereas I argue that sense-perceptual 
experience is permeated by perceptual awareness of oneself - the animal one is - as enjoying, suffering, reacting to, perhaps controlling that experience. That is an essential element of my argument that direct perceptual knowledge of our environment comes with knowledge that, and of how, we have that knowledge: we are perceptually aware of our cognitive relationship to the object of knowledge, a relation that includes the object's spatial and causal relation to our perceiving selves, and in particular to our sense organs. If anything is 'lived', it is our existence in the world as physical, bodily, animal (if also 'rational') beings. If that is not what we are, if what we experience ourselves to be is not a proper assumption as we go on to reflect on the human condition, then, as Descartes in his way recognised, we are victims of an extraordinarily comprehensive illusion. His employment of sceptical argument is intended to rid us of that supposed illusion - to lead the mind away from the senses, and from how our senses present us to ourselves as material individuals in a world in which we are surrounded by, and interacting with other 'bodies', material objects and stuffs.

\section{References}

Austin, John L. 1946. "Symposium: Other Minds II." Proceedings of the Aristotelian Society, Supplementary Volume 20, 148-187. Reprinted as "Other Minds" In: Austin, John L. 1979, Philosophical Papers, Oxford: Oxford University Press, 76-116.

Austin, John L. 1962. Sense and Sensibilia. Reconstructed from the manuscript notes by G.J. Warnock. Oxford: Oxford University Press.

Ayers, Michael 2004. "Sense experience, concepts and content - objections to Davidson and McDowell." In: Schumacher, Ralph (ed.), Perception and Reality. From Descartes to the Present. Paderborn: Mentis, 239-262.

Ayers, Michael 2005. "Ordinary objects, ordinary language, and identity." The Monist, 88(4), 534-570.

Ayers, Michael 2019. Knowing and Seeing. Groundwork for a New Empiricism. Oxford: Oxford University Press.

Ayer, A.J. 1940. The Foundations of Empirical Knowledge. New York: Macmillan.

Cunningham, J.J. 2018. "Are perceptual reasons the objects of perception?" In: Gersel, Johan, et al., (eds.), In the Light of Experience: New Essays in Perception and Reasons. Oxford: Oxford University Press, 256-279

Frege, Gottlob 1884. Die Grundlagen der Arithmetik. Breslau: Koebner. Translated by Austin, John L. 1968. The Foundations of Arithmetic: A Logico-Mathematical Enquiry into the Concept of Number. Oxford: Oxford University Press. 
Gettier, Edmund 1963. "Is justified true belief knowledge?" Analysis 23, 121-123.

McDowell, John 2011. Perception as a Capacity for Knowledge. Milwaukee, WI: Marquette University Press.

McDowell, John 2009. "The disjunctive conception of experience as material for a transcendental argument." In: The Engaged Intellect. Cambridge, MA: Harvard University Press, 223-240.

Travis, Charles 2021. "At Work in the Fields of the True." Grazer Philosophische Studien 98 (4), 561-558. 